\title{
ANALISIS ARUS KAS TERKAIT KEBIJAKAN UANG KULIAH TUNGGAL DI PERGURUAN TINGGI NEGERI BADAN HUKUM
}

\author{
Surtiati $^{* 1}$, Hermanto Siregar ${ }^{* *}$, dan Trias Andati $\left.{ }^{* * *}\right)$ \\ *) Biro Keuangan, Institut Pertanian Bogor \\ Gedung AHN Lt. 3, Kampus IPB Dramaga, Jl. Raya Dramaga Bogor 16680 \\ ${ }^{* *}$ Departemen Ilmu Ekonomi, Fakultas Ekonomi dan Manajemen, Institut Pertanian Bogor \\ Jl. Kamper, Wing 2 Level 5 Kampus IPB Darmaga, Bogor 16680 \\ ***) PT Adhimix Precast Indonesia \\ Jl. Raya Ps. Minggu No. 17 A, Pancoran Jakarta Selatan 12780
}

\begin{abstract}
The aims of the research were to analyze cash flow and compare tuition income in a State University with Legal Entity of "XYZ" for its first year TPB students (the First Common Year) and of the first year until the fourth year before and after implementation of the single tuition fee system and formulate the management policies for the tuition income after the single tuition fee system. Analysis of cash flows consisted of cash ratio, quick ratio and current ratio. Paired t-test was used to analyze differences between single tuition fee income and non single tuition fee income. Based on the cash flow analysis, it is found that the University of "XYZ" has a liquid financial condition. The significant difference is, moreover, detected from the paired $t$-test analysis between single and non single tuition fee of total income from the first year student tuition. However, there is no difference detected when the analysis was conducted for total income from all four year tuitions. Management policies tuition income after the single tuition fee system payment delays should be minimized so that tuition fee funds can be completely collected. The allocation of fees to the faculty/department was originally based on the BPMP, and BPMK uses a tariff system so that cost per subject does not necessarily correspond with the needs. This is not in accordance with the single tuition fee system that is based on the unit cost. This means that the cost of the course is based on real needs, not based on the rates set.
\end{abstract}

Keywords: cash flow analysis, state university with legal entity, single tuition fee

\begin{abstract}
ABSTRAK
Penelitian ini bertujuan menganalisis arus kas, mengkaji perbedaan penerimaan SPP SI Reguler satu tahun pertama bagi mahasiswa TPB dan tahun pertama sampai tahun ke empat sebelum dan sesudah kebijakan UKT di PTN Badan Hukum "XYZ. Selanjutnmya, merumuskan kebijakan pengelolaan SPP S1 reguler sesudah UKT. Analisis arus kas terdiri dari rasio kas, rasio cepat, dan rasio lancar. Analisis perbedaan penerimaan SPP S1 sebelum dan sesudah kebijakan UKT menggunakan uji t sampel berpasangan. Hasil penelitian menunjukkan bahwa berdasarkan analisis rasio arus kas PTN Badan Hukum "XYZ" memiliki rasio kas yang likuid. Hasil analisis uji t sampel berpasangan menunjukkan bahwa total penerimaan SPP S1 satu tahun pertama (TPB) sebelum dan sesudah UKT berbeda nyata sedangkan total penerimaan SPP SI dari tahun pertama hingga tahun ke empat sebelum dan sesudah UKT tidak berbeda nyata. Kebijakan pengelolaan SPP S1 reguler sesudah UKT sebaiknya penundaan pembayaran SPP diminimalisir agar dana SPP dapat terkumpul seutuhnya. Alokasi SPP ke fakultas/departemen semula berdasarkan BPMP dan BPMK menggunakan sistem tarif, sehingga biaya per mata kuliah belum tentu sesuai dengan kebutuhan. Hal ini tidak sesuai dengan sistem UKT yang didasarkan pada unit cost. Artinya, biaya mata kuliah didasarkan kepada kebutuhan riilnya, bukan berdasarkan tarif yang ditetapkan.
\end{abstract}

Kata kunci: analisis arus kas, perguruan tinggi negeri badan hukum, uang kuliah tunggal

\footnotetext{
${ }^{1}$ Alamat Korespondensi:

Email: surtiatiek16@gmail.com
} 


\section{PENDAHULUAN}

Disebutkan dalam UU No. 12 Tahun 2012 tentang Pendidikan Tinggi, salah satu asas dari pendidikan tinggi adalah keterjangkauan. Asas keterjangkauan adalah bahwa pendidikan tinggi diselenggarakan dengan biaya pendidikan yang ditanggung oleh mahasiswa sesuai dengan kemampuan ekonominya, orang tua atau pihak yang membiayainya untuk menjamin warga negara yang memiliki potensi dan kemampuan akademik memperoleh pendidikan tinggi tanpa hambatan ekonomi. Dalam UU No. 12 Tahun 2012 mengamanahkan kepada setiap pelaksanaan Pendidikan Tinggi perlu adanya standar biaya pendidikan yang terjangkau bagi mahasiswa dan orang tua mahasiswa sebagi donatur/pembiaya kuliah, hal ini tertuang pada pasal 88 ayat (4): "Biaya yang ditanggung oleh Mahasiswa sebagaimana dimaksud pada ayat (3) harus disesuaikan dengan kemampuan ekonomi mahasiswa, orang tua mahasiswa, atau pihak lain yang membiayainya". Usaha yang dilakukan oleh Pemerintah untuk menindaklanjuti hal tersebut lahirlah Peraturan Menteri Pendidikan dan Kebudayaan Republik Indonesia No. 55 Tahun 2013 tentang Biaya Kuliah Tunggal (BKT) dan Uang Kuliah Tunggal (UKT) pada seluruh Perguruan Tinggi Negeri (PTN) di Indonesia. BKT merupakan keseluruhan biaya operasional per mahasiswa per semester pada program studi di PTN. BKT digunakan sebagai dasar penetapan biaya yang dibebankan kepada mahasiswa masyarakat dan pemerintah. UKT merupakan sebagian BKT yang ditanggung setiap mahasiswa berdasarkan kemampuan ekonominya. UKT ditetapkan berdasarkan BKT dikurangi biaya yang ditanggung oleh pemerintah.

PTN Badan Hukum "XYZ" menyelenggarakan pendidikan akademik dan profesional. Penyelenggaraan pendidikan tersebut membutuhkan dana serta pengelolaan yang baik. Sumber pendapatan PTN Badan Hukum "XYZ" selengkapnya pada Tabel 1 dan 2. Berdasarkan Tabel 1 sumber pendapatan utama PTN Badan Hukum "XYZ" berasal dari Sumbangan Penyelenggaraan Pendidikan (SPP) \& Non SPP serta subsidi pemerintah. SPP \& Non SPP dari tahun 20112014 persentase penerimaannya adalah $32,1 \%, 34,3 \%$, $33,0 \%$ dan 33,7\%. Subsidi pemerintah dari tahun 20112014 persentase penerimaannya adalah sebesar 53,1\%, $48,3 \%, 44,6 \%$ dan 44,0\%. Pada Tabel 2 terlihat SPP Sarjana Reguler merupakan pendapatan terbesar kedua setelah SPP Pascasarjana Reguler. Tahun 2011, 2012 persentase penerimaan sebesar $20,8 \%, 22,9 \%$. Tahun 2013 dan 2014 naik menjadi 24,2\% dan 28,4\%. Sebelum UKT, PTN menentukan sendiri komponen biaya kuliah yang harus dibayarkan oleh mahasiswa. Komponen biaya kuliah disajikan pada Tabel 3.

Tabel 1. Pendapatan PTN Badan Hukum "XYZ"

\begin{tabular}{lrrrrrrrr}
\hline \multirow{2}{*}{ Pendapatan } & \multicolumn{2}{c}{2011} & \multicolumn{2}{c}{2012} & \multicolumn{2}{c}{2013} & \multicolumn{2}{c}{2014} \\
\cline { 2 - 9 } & \multicolumn{1}{c}{ Rp juta } & \multicolumn{1}{c}{ Rp juta } & \multicolumn{1}{c}{$\%$} & Rp juta & \multicolumn{1}{c}{$\%$} & \multicolumn{1}{c}{ Rp juta } & \multicolumn{1}{c}{$\%$} \\
\hline SPP dan Non SPP & 249.063 & 32,1 & 260.922 & 34,3 & 261,680 & 33,0 & 284,160 & 33,7 \\
Hibah & 8.459 & 1,09 & 16.563 & 2,18 & - & - & 5.998 & 0,7 \\
Kerja sama & 99.813 & 12,86 & 107.370 & 14,12 & 155.360 & 19,61 & 152.622 & 18,1 \\
Usaha Komersial & 850 & 0,11 & 850 & 0,11 & 2.767 & 0,35 & 3.825 & 0,5 \\
Usaha Penunjang & 5.503 & 0,71 & 7.136 & 0,94 & 18.935 & 2,39 & 26.024 & 3,1 \\
Subsidi Pemerintah & 412.215 & 53,13 & 367.667 & 48,34 & 353.589 & 44,63 & 371.688 & 44,0 \\
\hline \multicolumn{1}{c}{ Jumlah } & 775.903 & 100,00 & 760.509 & 100,00 & 792.330 & 100,00 & 844.316 & 100,00 \\
\hline
\end{tabular}

Tabel 2. SPP PTN Badan Hukum "XYZ"

\begin{tabular}{lrrrrrrrr}
\hline \multirow{2}{*}{\multicolumn{1}{c}{ SPP dan Non SPP }} & \multicolumn{2}{c}{2011} & \multicolumn{2}{c}{2012} & \multicolumn{2}{c}{2013} & \multicolumn{2}{c}{2014} \\
\cline { 2 - 9 } & \multicolumn{1}{c}{ Rp juta } & \multicolumn{1}{c}{$\%$} & Rp juta & \multicolumn{1}{c}{ Rp juta } & $\%$ & Rp juta & $\%$ \\
\hline Pascasarjana Reguler & 56.844 & 22,8 & 47.336 & 18,1 & 84.349 & 32,2 & 77.166 & 27,2 \\
Sarjana Reguler & 51.800 & 20,8 & 59.701 & 22,9 & 63.338 & 24,2 & 80.798 & 28,4 \\
Diploma berbasis Direktorat & 38.448 & 15,4 & 39.030 & 15,0 & 49.942 & 19,1 & 54.084 & 19,0 \\
Program Sarjana BUD & 16.071 & 6,5 & 17.458 & 6,7 & 19.158 & 7,3 & 16.673 & 5,9 \\
Program Manajemen Bisnis & 16.017 & 6,4 & 17.820 & 6,8 & 16.445 & 6,3 & 23.058 & 8,1 \\
Lain-lain & 12.592 & 5,1 & 11.668 & 4,5 & 15.513 & 5,9 & 14.095 & 5,0 \\
Non SPP & 57.291 & 23,0 & 67.908 & 26,0 & 12.936 & 4,9 & 18.286 & 6,4 \\
\hline \multicolumn{1}{c}{ Jumlah } & 249.063 & 100 & 260.922 & 100 & 261.680 & 100 & 284.160 & 100 \\
\hline
\end{tabular}


Tabel 3. Komponen Biaya Kuliah Program S1 sebelum UKT (dalam ribu rupiah)

\begin{tabular}{cllrrrrc}
\hline \multirow{2}{*}{$\begin{array}{c}\text { Kelompok } \\
\text { Pembayaran }\end{array}$} & Penghasilan Kotor & \multicolumn{3}{c}{ Biaya Registrasi Mahasiswa Baru } & \multicolumn{2}{c}{ SPP per Tahun } \\
\cline { 5 - 8 } & Orang Tua/Wali (P) & BPMB & AI & POM & BPIF & BPMP & BPMK \\
\hline I & P $\leq 500$ & & & 0 & 0 & 0 & Tahun \\
II & $500<\mathrm{P} \leq 1.000$ & & & 350 & 1.500 & 1.000 & Pertama: \\
III & $1.000<\mathrm{P} \leq 2.500$ & & & 400 & 3.500 & 1.600 & 1.130 \\
IV & $2.500<\mathrm{P} \leq 5.000$ & \multirow{2}{*}{800} & 500 & 450 & 6.500 & 2.400 & \\
V & $5.000<\mathrm{P} \leq 7.500$ & & & 500 & 10.500 & 3.400 & Tahun \\
VI & $7.500<\mathrm{P} \leq 10.000$ & & & 550 & 15.500 & 4.600 & Berikunya: \\
VII & $10.000<\mathrm{P} \leq 15.000$ & & & 650 & 20.000 & 5.800 & 20 - 50 / sks \\
VIII & $\mathrm{P} \geq 15.000$ & & 750 & 24.500 & 7.000 & \\
\hline
\end{tabular}

Tabel 4. UKT per semester (dalam ribu rupiah)

\begin{tabular}{clrrr}
\hline Kelompok & \multicolumn{1}{c}{ Penghasilan Kotor } & \multicolumn{3}{c}{ Kelompok Program Studi } \\
\cline { 3 - 5 } Pembayaran & Orang Tua/Wali (P) & Sosial Ekonomi & Teknologi & Kedokteran \\
\hline I & $\mathrm{P} \leq 500$ & 500 & 500 & 500 \\
II & $500<\mathrm{P} \leq 1.000$ & 1.000 & 1.000 & 1.000 \\
III & $1.000<\mathrm{P} \leq 2.500$ & 2.400 & 2.400 & 2.600 \\
IV & $2.500<\mathrm{P} \leq 5.000$ & 3.100 & 3.800 & 4.500 \\
V & $5.000<\mathrm{P} \leq 7.500$ & 3.700 & 5.200 & 6.750 \\
VI & $7.500<\mathrm{P} \leq 10.000$ & 4.300 & 6.600 & 9.000 \\
VII & $10.000<\mathrm{P} \leq 15.000$ & 4.900 & 8.100 & 11.250 \\
VIII & $\mathrm{P} \geq 15.000$ & 5.500 & 9.600 & 13.500 \\
\hline
\end{tabular}

Komponen biaya kuliah (Tabel 3) dibayarkan berdasarkan kelompokkan pembayarn sesuai dengan penghasilan orang tua/wali. Di PTN Badan Hukum "XYZ" berdasarkan Surat Keputusan (SK) Rektor No. 018/I3/KU/2011 untukTahunAkademik(TA)2011/2012 dan TA 2012/2013 bagi mahasiswa baru Program S1 reguler pada satu tahun pertama dikenakan biaya registrasi dan biaya pendidikan. Biaya registrasi terdiri atas Biaya Perlengkapan Mahasiswa Baru (BPMB), Akses Layanan Internet (AI), Iuran Perhimpunan Orang Tua Mahasiswa (POM). Untuk biaya pendidikan, menurut SK Rektor No. 047/K13/PP/2005 terdiri atas SPP (Biaya Peningkatan Mutu Pendidikan (BPMP) dan Biaya Penyelenggaraan Mata Kuliah (BPMK) satu tahun pertama mahasiswa Tingkat Persiapan Bersama (TPB), Iuran Pembangunan Fasilitas Pendidikan (IPFP) berubah nama menjadi Biaya Pengembangan Institusi dan Fasilitas (BPIF) berdasarkan SK Rektor No. 014/ I3/KU/2011. Selanjutnya untuk tahun kedua hingga keempat mahasiswa hanya membayar BPMP dan BPMK. Berdasarkan SK Rektor No. 143//3/PP/2010 tentang Biaya BPMP dan BPMK Program Pendidikan Sarjana, BPMP dialokasikan untuk departemen, fakultas dan rektorat, sedangkan BPMK seluruhnya dialokasikan ke departemen/fakultas sebagai pengampu atau penyelenggara mata kuliah. TA 2013/2014 mulai diberlakukan UKT untuk mahasiswa baru di seluruh PTN di Indonesia. PTN Badan Hukum "XYZ" merupakan salah satu PTN yang juga menerapkan kebijakan UKT. Berikut tarif UKT Di PTN Badan Hukum "XYZ" dapat dilihat pada Tabel 4.

Pada Tabel 4 terlihat tarif UKT di PTN Badan Hukum "XYZ" terbagi dalam 3 kelompok Program Studi (PS) yakni Sosial Ekonomi, Teknologi, dan Kedokteran. Tarif UKT dibayarkan berdasarkan kelompokkan pembayarn sesuai dengan penghasilan orang tua/wali. Bagi mahasiswa baru untuk satu tahun pertama tidak dikenakan lagi uang gedung dan segala pungutan lain karena semua dijadikan satu pembayaran bernama UKT. Selanjutnya untuk tahun kedua hingga keempat, tarif yang dibayarkan tetap sesuai dengan kelompok PS.

Kebijakan UKT diterapkan dimana mahasiswa sudah tidak dikenakan lagi uang pangkal atau biaya pengembangan fasilitas. Karena adanya perbedaan tersebut diduga dapat mengakibatkan penurunan jumlah penerimaan SPP dan hal ini berpotensi mengganggu arus kas sehingga berdampak pada berkurangnya 
anggaran. Penelitian arus kas terkait kebijakan UKT penting dilakukan untuk mengetahui dampak dan kendala penerapan kebijakan UKT di PTN Badan Hukum "XYZ". Menurut Lubis dan Sujianto (2014) dalam penelitiannya yang dilakukan di Universitas Riau menyatakan dampak atas pelaksanaan UKT yaitu anggaran pendapatan Universitas Riau menurun. Penerapan UKT ternyata menyebabkan universitas yang menerapkannya mengalami defisit pendapatan pada tahun pertama hingga tahun ketiga dan akan kembali stabil setelah menjalankan sistem ini selama 4 tahun penerapan. Ini dapat menyebabkan pendanaan kegiatan mahasiswa akan relatif lebih kecil dari tahun-tahun sebelumnya.

Mengingat penerimaan Sumbangan Penyelenggaraan Pendidikan (SPP) merupakan sumber pendapatan terbesar kedua setelah subsidi pemerintah, dimana subsidi pemerintah tersebut persentase penerimaannya menurun dari tahun 2011-2014, maka penerimaan SPP khususnya SPP S1 Reguler berperan penting terhadap terpenuhinyakebutuhan oprasionaldiPTNBadanHukum "XYZ". Hal ini selaras dengan pernyataan Astuti et al. (2015) yang menyatakan bahwa dalam mencapai tujuan PT diperlukan sumberdaya yang meliputi keuangan, teknologi dan SDM. Sumber dana yang diperlukan berasal dari dana masyarakat (SPP mahasiswa) dan dari kegiatan kerjasama. Selain itu sebagai dasar bagi pihak manajemen keuangan dalam pengambilan keputusan, merencanakan dan mengalokasikan anggaran.

Terkait dengan latar belakang tersebut, perlu dilakukan penelitian yang bertujuan menganalisis arus kas, menganalisis perbedaan penerimaan SPP S1 Reguler untuk satu tahun pertama bagi mahasiswa TPB dan untuk tahun pertama sampai tahun ke empat sebelum dan sesudah diberlakukannya kebijakan UKT serta merumuskan kebijakan pengelolaan SPP S1 reguler sesudah UKT. Ruang lingkup penelitian meliputi periode sebelum UKT, yaitu TA 2011/2012 dan TA 2012/2013, sedangkan sesudah UKT yaitu TA 2013/2014 dan TA 2014/2015.

\section{METODE PENELITIAN}

Obyek penelitian adalah SPP S1 reguler sebelum dan sesudah kebijakan UKT yang dikelompokkan kedalam sembilan fakultas. Data yang digunakan dalam penelitian iniadalah data primerdan sekunder. Data primerdiperoleh dengan teknik observasi langsung ke lokasi dan obyek penelitian, wawancara langsung dengan pimpinan yang terdiri dari Direktur Perencanaan dan Pengembangan, Kepala Biro Keuangan dan pada masing-masing bagian yang ada di Biro Keuangan, yakni Kepala Bagian Pendapatan, Kepala Bagian Perbendaharaan, Kepala Bagian Pengendalian Anggaran dan Pelaporan, Kepala Subbagian Pengendalian, Kepala Subbagian Pelaporan Keuangan, Kepala Subbagian Pendapatan Pendidikan, Bendahara Penerima dan Bendahara Pengeluaran. Data sekunder berupa laporan keuangan audited tahun 2011-2014, jumlah mahasiswa TPB sebelum UKT TA 2011/2012 dan TA 2012/2013 dan setelah UKT TA 2013/2014 dan TA 2014/2015, komponen biaya pendidikan sebelum dan sesudah UKT, tarif BPMP dan BPMK dari semester tiga sampai delapan. Data lainnya diperoleh dari kebijakan manajemen keuangan PTN Badan Hukum "XYZ", buku, jurnal, penelitian terdahulu dan sumber lain yang berhubungan dengan topik dan masalah penelitian ini.

Kerangka pemikiran (Gambar 1) disusun berdasarkan tujuan penelitian dan berfungsi sebagai tahapan penelitian. Penelitian dimulai dengan mempelajari kebijakan UKT dan selanjutnya dilakukan analisis arus kas untuk melihat kemampuan PTN Badan Hukum "XYZ" dalam memenuhi kebutuhan operasionalnya. SPP S1 Reguler merupakan salah satu komponen penerimaan. Dengan adanya kebijakan UKT diduga jumlah penerimaan tersebut menurun. Oleh karena itu dilakukan perbandingan antara penerimaan SPP S1 Reguler sebelum dan sesudah UKT. Hasil perbandingan tersebut serta permasalahan yang terkait dengan kebijakan UKT menjadi dasar perumusan kebijakan pengelolaan SPP S1 Reguler setelah UKT dan penyusunan implikasi manajerial.

Penelitian ini menggunakan metode deskriptif serta pengujian statistika. Pengujian statistik terhadap penerimaan SPP S1 reguler sebelum dan sesudah UKT dilakukan dengan uji t untuk sampel berpasangan dengan bantuan SPSS (Statistical Package for the Social Science) ver 15 dengan taraf kepercayaan 95\% (taraf signifikan $\alpha=0,05)$. Uji t bertujuan untuk mengetahui ada tidaknya perbedaan nyata dalam hal penerimaan SPP S1 reguler sebelum dan sesudah kebijakan UKT. Hipotesis dalam penelitian ini adalah sebagai berikut:

H0 : Tidak terdapat perbedaan total penerimaan SPP TPB sebelum dan sesudah kebijakan UKT

H1 : Terdapat perbedaan total penerimaan SPP TPB sebelum dan sesudah kebijakan UKT 
H0 : Tidak terdapat perbedaan total penerimaan SPP tahun pertama hingga tahun ke empat sebelum dan sesudah kebijakan UKT

H1 : Terdapat perbedaan total penerimaan SPP mulai tahun pertama hingga tahun ke empat sebelum dan sesudah kebijakan UKT

Pertama uji $t$ terhadap total penerimaan SPP S1 mahasiswa TPB satu tahun pertama sebelum dan sesudah UKT. Sebelum UKT data yang digunakan adalah jumlah mahasiswa TPB TA 2011/2012 dan TA 2012/2013 setiap fakultas yang dikelompokkan sesuai dengan golongan penghasilan orang tua dikali jumlah komponen biaya yang terdapat pada Tabel 3, terdiri dari biaya registrasi sesuai dengan SK Rektor No. 018/ I3/PP/2011 tentang Biaya Registrasi Mahasiswa Baru Program Pendidikan Sarjana (S1) dan SPP satu tahun pertama yang terdiri dari BPMP dan BPMK sesuai dengan SK Rektor No. 079/I3/PP/2011 tentang BPMK bagi Program Pendidikan Tingkat Persiapan Bersama. Setelah UKT data yang digunakan adalah UKT sesuai dengan Program Studi ditambah biaya asrama dan deposit asrama yang terdapat pada Tabel 4, dikali dengan jumlah mahasiswa TPB TA 2013/2014 dan TA 2014/2015 setiap fakultas yang dikelompokkan sesuai dengan golongan penghasilan orang tua.

Selanjutnya uji $\mathrm{t}$ terhadap total penerimaan SPP mahasiswa keseluruhan mulai tahun pertama hingga tahun ke empat sebelum dan sesudah UKT. Sebelum UKT data yang digunakan adalah jumlah mahasiswa TPB TA 2011/2012 dan TA 2012/2013 setiap fakultas yang dikelompokkan sesuai dengan golongan penghasilan orang tua. Perhitungan dilakukan dengan cara menjumlahkan biaya kuliah dari tahun pertama hingga tahun keempat lalu dikalikan dengan jumlah mahasiswa. Biaya tahun pertama menggunakan data yang terdapat pada Tabel 3, sedangkan data untuk tahun kedua hingga keempat dengan menghitung BPMP dan BPMK setiap semester. BPMK diperoleh dengan cara menghitung bobot SKS mata kuliah dikali tarif per SKS yang telah ditetapkan sesuai SK Rektor No. 128/ I3/PP/2008 BPMK bagi mahasiswa semester 3 dan 5, SK Rektor No. 002/I3/PP/2009 BPMK bagi mahasiswa semester 4 dan 6, SK Rektor No. 127/I3/PP/2008 BPMK bagi mahasiswa semester 7 dan SK Rektor No. 001/I3/PP/2009 BPMK bagi mahasiswa semester 8 .

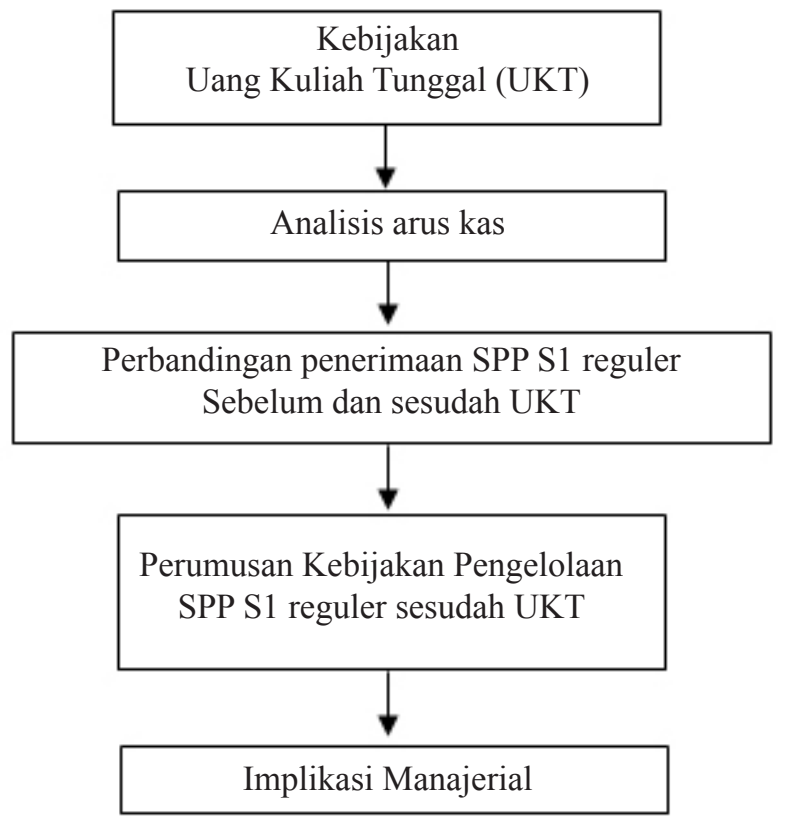

Gambar 1. Kerangka pemikiran penelitian

\section{HASIL}

\section{Analisis Arus Kas}

PTN Badan Hukum "XYZ" bergerak dalam bidang pendidikan akademik dan profesional mengelola sembilan fakultas. Penyelenggaraan pendidikan tersebut membutuhkan kas serta pengelolaan kas yang baik. Sebagai organisasi bersifat nirlaba memerlukan kas yang cukup untuk menyelenggarakan kegiatan operasional pendidikan multistrata. Kas merupakan harta yang paling likuid dalam perusahaan karena arus kas merupakan nyawa bagi setiap perusahaan. Salah satu analisis kinerja keuangan dengan menggunakan laporan arus kas adalah rasio analisis arus kas (Subani, 2015). Berdasarkan data dari laporan keuangan audited tahun 2011-2014, dihasilkan analisis arus kas dengan menggunakan rasio likuiditas. Rasio likuiditas yang digunakan meliputi:

\section{Rasio Lancar (current ratio)}

Rasio lancar PTN Badan Hukum "XYZ" selama empat tahun mengalami fluktuasi (Gambar 2). Hal ini disebabkan adanya kenaikan dan penurunan aset lancar dan kewajiban jangka pendek. Secara keseluruhan walaupun mengalami fluktuasi, rasio lancar adalah baik karena diatas $200 \%$. Artinya, mampu untuk melunasi kewajiban jangka pendek. Rasio lancar tertinggi terjadi pada tahun 2013 sebesar 4,72 atau $472 \%$. Persentase 
tersebut dihasilkan dari perbandingan antara aset lancar sebesar Rp264.651.697.789 dengan hutang lancar sebesar Rp56.055.483.576 dikali 100\%. Berikut perkembangan rasio lancar PTN Badan Hukum "XYZ" dapat dilihat pada Gambar 2.

\section{Rasio Cepat (Quick ratio)}

Quick ratio adalah merupakan rasio antara aktiva lancar sesudah dikurangi persediaan dengan hutang lancar. Rasio ini menunjukkan besarnya alat likuid yang paling cepat yang bisa digunakan untuk melunasi hutang lancar. Persediaan dianggap aktiva lancar yang paling tidak lancar. Secara keseluruhan rasio cepat adalah baik karena diatas $100 \%$. Artinya, PTN Badan Hukum "XYZ" mampu untuk melunasi kewajiban jangka pendeknya dengan aktiva lancar yang dimilikinya setelah dikurangi persediaan. Rasio cepat tertinggi terjadi pada tahun 2013 sebesar 4,70 atau $470 \%$. Persentase tersebut dihasilkan dari perbandingan antara aktiva lancar sesudah dikurangi persediaan sebesar Rp263.380.968.710 dengan hutang lancar sebesar Rp56.055.483.576 dikali 100\%. Berikut perkembangan rasio cepat PTN Badan Hukum "XYZ" dapat dilihat pada Gambar 3.

\section{Rasio Kas (Cash ratio)}

Cash ratio adalah rasio yang membandingkan antara kas dan aktiva lancar yang bisa segera menjadi uang kas dengan hutang lancar. Aktiva lancar yang bisa segera menjadi uang kas adalah efek atau surat berharga. Rasio kas dari tahun 2011 hingga 2013 mengalami kenaikan terus menerus dan mengalami penurunan menjadi 3,92 pada tahun 2014. Rasio kas tertinggi pada tahun 2013, sebesar 4,29 atau 429\%. Persentase tersebut dihasilkan dari perbandingan antara kas dan aktiva lancar sebesar Rp240.718.544.498 dengan hutang lancar sebesar Rp56.055.483.576 dikali 100\%. Angka pada rasio tersebut menunjukkan PTN Badan Hukum "XYZ" mampu membayar kewajiban lancarnya dengan menggunakan kas yang dimilikinya. Berikut perkembangan rasio kas PTN Badan Hukum "XYZ" dapat dilihat pada Gambar 4.

Sejauh ini PTN Badan Hukum "XYZ" bisa tetap mencukupi kebutuhan operasional dan program yakni dengan adanya kebijakan pengelolaan kas yang meliputi kebijakan penerimaan dan pengeluaran yang tertuang dalam Perencanaan Strategi (Renstra). Kebijakan ini adalah strategi manajemen keuangan PTN Badan
Hukum "XYZ". Strategi ini sudah dilaksanakan sejak sebelum kebijakan UKT diberlakukan dan masih tetap dilaksanakan sampai saat ini. Strategi administrasi PTN Badan Hukum "XYZ" secara umum berupa: 1) Sentralisasi Administrasi Desentralisasi Akademik dan Riset (SADAR); 2) Perencanaan di PTN Badan Hukum "XYZ" menggunakan pendekatan partisipatif, yakni melibatkan seluruh unit kerja melalui kegiatan Musyawarah Perencanaan dan Pengembangan (Musrenbang) yang bersifat bottom up and top down planning yaitu mensinergikan antara program nasional, kebijakan pimpinan dengan inisiatif masing-masing unit kerja yang dikemas dalam satu kesatuan untuk menuju kepada sasaran program dan kegiatan yang telah ditetapkan dan disepakati bersama. Hal ini selaras dengan pernyataan Retnani (2009) yang menyatakan Proses pengajuan program kerja dan anggaran di Perguruan Tinggi Swasta "X" adalah partisipatif atau menggunakan pendekatan bottom up. Partisipasi bawahan diperlukan dalam penyusunan program kerja dan anggaran, karena anggaran sangat berpengaruh terhadap perilaku manajer pusat pertanggung jawaban atau pimpinan Unit Satuan Kerja sehingga konflik antara tujuan individu dengan tujuan organisasi dapat dikurangi; 3) Kebijakan perencanaan secara makro PTN Badan Hukum "XYZ" tertuang dalam Rencana Kerja Anggaran Tahunan (RKAT). RKAT digunakan sebagai acuan pelaksanaan kegiatan dan anggaran. Menurut Wagh dan Gadade (2014) sistem kontrol anggaran memotivasi serta memonitor semua kegiatan dan personil untuk melakukan semua kegiatan keuangan secara terpola dan sistematis. Kegiatan yang terdapat dalam RKAT bersifat umum sehingga rincian detail kegiatan ditentukan oleh unit kerja yang melaksanakannya dan dituangkan dalam bentuk Term of Reference (TOR); 4) Standar baku disusun untuk memonitor dan mengevaluasi (monev) penggunaan dana unit kerja di lingkungan PTN Badan Hukum "XYZ" agar efisien dan mencapai sasaran yang diinginkan.

\section{Perbedaan Penerimaan SPP Program S1 Reguler Sebelum dan Sesudah UKT}

Secara umum, hasil analisis arus kas PTN Badan Hukum "XYZ" adalah liquid artinya mampu untuk memenuhi kebutuhan jangka pendek. Namun, berdasarkan hasil uji t terhadap salah satu komponen utama penerimaan (SPP S1 Reguler), terdapat perbedaan penerimaan SPP S1 Reguler sebelum dan sesudah kebijakan UKT. Berikut ringkasan hasil uji t pada Tabel 5. 


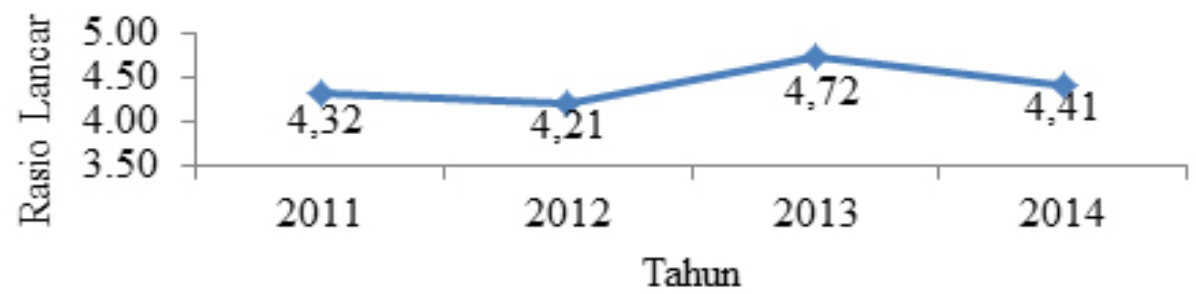

Gambar 2. Grafik rasio lancar tahun 2011-2014

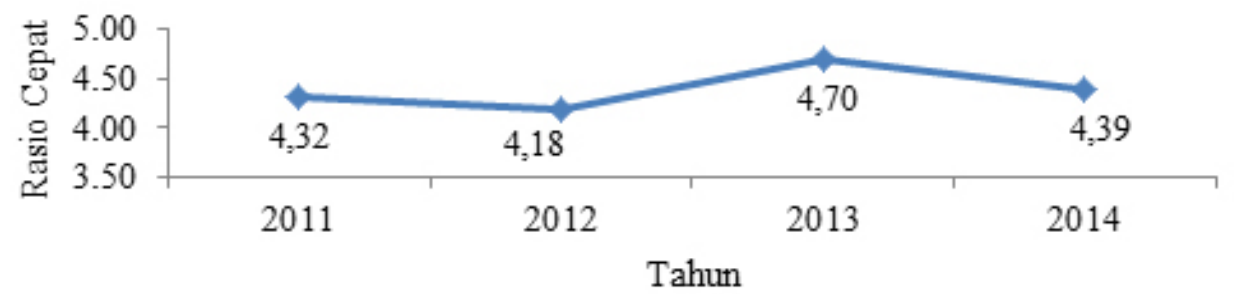

Gambar 3. Grafik rasio cepat tahun 2011-2014

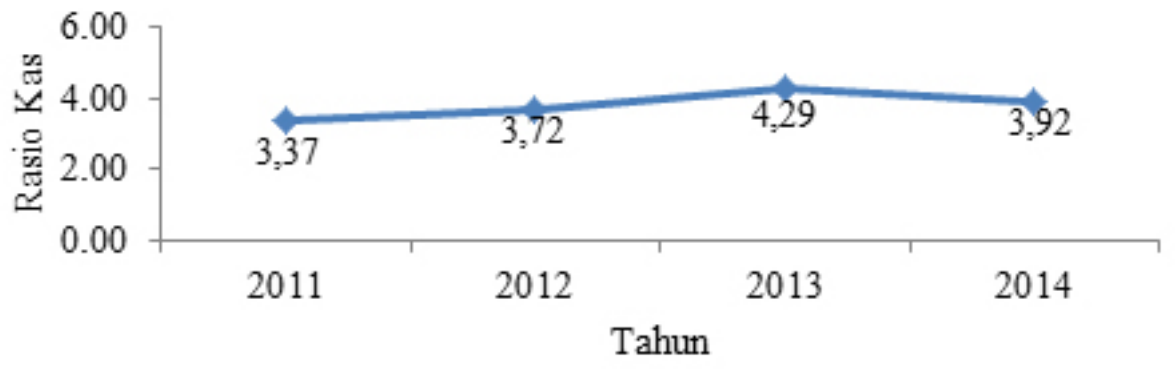

Gambar 4. Grafik rasio kas tahun 2011-2014

Berdasarkan Tabel 5, total penerimaan SPP S1 Reguler (TPB) satu tahun sebelum dan sesudah UKT berbeda nyata. Berdasarkan hasil uji t (TPB satu tahun sebelum UKT menghasilkan 53067,03 $\pm 3599,75^{\text {a }}$ ) dan (TPB satu tahun sesudah UKT menghasilkan 33702,80 \pm $3120,04^{\text {b }}$. Berbeda nyata disebabkan karena sebelum UKT mahasiswa baru pada satu tahun pertama harus membayar BPIF, SPP (BPMP dan BPMK), BPMB, POM dan AI. Biaya-biaya tersebut harus dibayarkan oleh mahasiswa sekurang-kurangnya $70 \%$ dari total biaya pendidikan tahun pertama. Sedangkan setelah UKT komponen biaya tersebut dikumpulkan menjadi satu lalu dibagi merata ke 8 semester, sehingga jumlah yang dibayarkan pada tahun pertama menjadi lebih kecil. Hal ini selaras dengan pernyataan Lubis dan Sujianto (2014) yang menyatakan jika diperhatikan sekilas UKT memang meringankan mahasiswa baru, yakni biaya pendidikan dibagi secara merata selama masa kuliah sehingga nominalnya akan menjadi lebih kecil pada semester pertama.
Berdasarkan Tabel 5, total penerimaan SPP S1 Reguler mulai tahun pertama hingga tahun ke empat sebelum dan sesudah UKT tidak berbeda nyata. Berdasarkan hasil uji $\mathrm{t}$ (Keseluruhan tahun 1-4 sebelum UKT menghasilkan $128691,97 \pm 10286,63^{\mathrm{a}}$ ) dan (Keseluruhan tahun 1-4 sesudah UKT menghasilkan 133741,60 $\pm 10951,67^{\mathrm{a}}$ ). Tidak berbeda nyata disebabkan biaya kuliah pada saat sebelum dan sesudah UKT jika diakumulasikan jumlahnya tidak jauh berbeda. Hal ini sependapat dengan Lubis dan Sujianto (2014) menyebutkan bahwa sesungguhnya beban yang ditanggung selama kuliah tetaplah sama.

Sumbangan Penyelenggaraan Pendidikan (SPP) sebagai sumber utama penerimaan dibayarkan berdasarkan kemampuan masyarakat. Sebelum dan sesudah UKT PTN Badan Hukum "XYZ" mengelompokkan pembayaran SPP berdasarkan penghasilan kotor orang tua/wali menjadi 8 kelompok. Pengelompokkan tersebut menganut prinsip subsidi 
silang. Subsidi silang bertujuan mengembangkan sistem yang lebih berkeadilan dengan memperbesar subsidi kepada mereka yang lebih membutuhkan dan mengurangi subsidi kepada mereka yang kurang membutuhkan. Kebijakan ini tidak ditujukan untuk memperbesar penerimaan SPP melainkan mendorong mereka yang lebih kuat secara ekonomi memberikan kontribusi lebih besar.

Berdasarkan Tabel 6, jika dilihat dari kelompok pembayaran, penerimaan SPP sebelum UKT tahun 2011 didominasi oleh kelompok III, IV dan V dengan total persentase sebesar $65,11 \%$ dan tahun 2012 kelompok III, IV, dan V mengalami penurunan dengan total persentase sebesar 50,96\%, namun ada peningkatan sebesar $11,36 \%$ di kelompok VI. Sesudah UKT penerimaan SPP didominasi oleh kelompok IV,
V, dan VI dengan total persentase sebesar $49,76 \%$ pada tahun 2013 dan 48,11\% pada tahun 2014. Hal ini berarti sesudah UKT, walaupun SPP UKT besarannya menurun, namun jumlah penerimaan SPP yang berasal dari kelompok pembayaran penghasilan orang tuanya tinggi meningkat.

Pihak manajemen PTN Badan Hukum "XYZ" memposisikan mahasiswa Bidik Misi diluar kelompok pembayaran I - VIII. Hal ini karena Bidik Misi merupakan program beasiswa dari pemerintah diberikan kepada mahasiswa yang memiliki prestasi akademik tinggi namun kurang mampu secara ekonomi. Hasil uji $\mathrm{t}$ terhadap total penerimaan SPP S1 Reguler sebelum dan sesudah UKT dipengaruhi oleh SPP Bidik Misi yang besarannya sama pada saat sebelum dan sesudah UKT.

Tabel 5. Ringkasan uji t dari penerimaan SPP S1 Reguler (dalam juta rupiah)

\begin{tabular}{|c|c|c|c|c|c|c|c|c|c|c|c|c|}
\hline \multirow{3}{*}{$\begin{array}{c}\text { Kode } \\
\text { Fakultas }\end{array}$} & \multicolumn{6}{|c|}{ TPB satu tahun } & \multicolumn{6}{|c|}{ Keseluruhan tahun $1-4$} \\
\hline & \multicolumn{3}{|c|}{ Sebelum UKT } & \multicolumn{3}{|c|}{ Sesudah UKT } & \multicolumn{3}{|c|}{ Sebelum UKT } & \multicolumn{3}{|c|}{ Sesudah UKT } \\
\hline & Mean & \pm & $\begin{array}{c}\text { Std. } \\
\text { Deviation }\end{array}$ & Mean & \pm & $\begin{array}{c}\text { Std. } \\
\text { Deviation }\end{array}$ & Mean & \pm & $\begin{array}{c}\text { Std. } \\
\text { Deviation }\end{array}$ & Mean & \pm & $\begin{array}{c}\text { Std. } \\
\text { Deviation }\end{array}$ \\
\hline A & $6.177,34$ & \pm & $477,89^{\text {a }}$ & $3.854,30$ & \pm & $160,51^{\mathrm{b}}$ & $15.064,75$ & \pm & $1.244,45^{\mathrm{a}}$ & $15.417,20$ & \pm & $642,05^{\mathrm{a}}$ \\
\hline B & $2.996,44$ & \pm & $456,81^{\mathrm{a}}$ & $2.760,25$ & \pm & $719,62^{a}$ & $7.132,09$ & \pm & $1.066,01^{\mathrm{a}}$ & $11.041,00$ & \pm & $2.878,49^{\mathrm{a}}$ \\
\hline $\mathrm{C}$ & $5.536,91$ & \pm & $128,72^{\mathrm{a}}$ & $3.882,10$ & \pm & $136,47^{\mathrm{b}}$ & $13.888,41$ & \pm & $629,44^{\mathrm{a}}$ & $14.453,20$ & \pm & $974,68^{\mathrm{a}}$ \\
\hline $\mathrm{D}$ & $2.787,20$ & \pm & $447,24^{\mathrm{a}}$ & $1.746,50$ & \pm & $5,23^{\mathrm{a}}$ & $6.747,92$ & \pm & $1.150,42^{\mathrm{a}}$ & $6.986,00$ & \pm & $20,93^{\mathrm{a}}$ \\
\hline E & $5.221,40$ & \pm & $135,57^{\mathrm{a}}$ & $3.538,20$ & \pm & $485,36^{\mathrm{b}}$ & $12.977,88$ & \pm & $576,72^{\mathrm{a}}$ & $14.152,80$ & \pm & $1.941,43^{\mathrm{a}}$ \\
\hline $\mathrm{F}$ & $7.078,41$ & \pm & $298,62^{a}$ & $4.488,25$ & \pm & $232,85^{\mathrm{b}}$ & $16.876,15$ & \pm & $895,41^{\mathrm{a}}$ & 3,00 & \pm & $931,40^{\mathrm{a}}$ \\
\hline G & $9.075,36$ & \pm & $438,39^{\mathrm{a}}$ & $6.036,40$ & \pm & $39,94^{b}$ & $22.441,29$ & \pm & $1.564,87^{\mathrm{a}}$ & $24.145,60$ & \pm & $1.597,50^{\mathrm{a}}$ \\
\hline $\mathrm{H}$ & $8.811,72$ & \pm & $602,38^{a}$ & $4.341,05$ & \pm & $768,27^{\mathrm{b}}$ & $20.461,32$ & \pm & $1.634,18^{\mathrm{a}}$ & $17.367,40$ & \pm & $3.068,56^{\mathrm{a}}$ \\
\hline I & $5.382,27$ & \pm & $614,13^{a}$ & $3.055,72$ & \pm & $222,81^{b}$ & $13.102,16$ & \pm & $1.525,13^{\mathrm{a}}$ & $12.225,40$ & \pm & $887,84^{\mathrm{a}}$ \\
\hline Total & $53.067,03$ & \pm & $599,72^{\mathrm{a}}$ & 702,80 & \pm & $3.120,04^{b}$ & $28.691,97$ & \pm & $10.286,63^{\mathrm{a}}$ & $13.3741,60$ & \pm & $10.951,67^{\mathrm{a}}$ \\
\hline
\end{tabular}

Keterangan: a,b Superskrip yang berbeda pada baris yang sama menunjukkan berbeda nyata pada taraf $\alpha=0,05$

Sumber: Biro Keuangan PTN Badan Hukum "XYZ” (data diolah)

Tabel 6. Jumlah mahasiswa TPB berdasarkan kelompok penghasilan orang tua

\begin{tabular}{clrrrrrrrr}
\hline \multirow{2}{*}{$\begin{array}{c}\text { Kelompok } \\
\text { Pembayaran }\end{array}$} & Penghasilan Kotor & \multicolumn{9}{c}{ Sebelum UKT } & \multicolumn{5}{c}{ Sesudah UKT } \\
\cline { 3 - 10 } & Orang Tua/Wali (P) & \multicolumn{1}{c}{$\%$} & \multicolumn{1}{c}{ Mahasiswa TPB } \\
\cline { 3 - 10 } & Bidik Misi & 500 & 15,41 & 1.100 & 30,70 & 954 & 26,09 & 874 & 24,88 \\
I & P $\leq 500$ & 24 & 0,74 & 8 & 0,22 & 17 & 0,46 & 16 & 0,46 \\
II & $500<\mathrm{P} \leq 1.000$ & 108 & 3,33 & 40 & 1,12 & 50 & 1,37 & 39 & 1,11 \\
III & $1.000<\mathrm{P} \leq 2.500$ & 508 & 15,66 & 278 & 7,76 & 320 & 8,75 & 271 & 7,71 \\
IV & $2.500<\mathrm{P} \leq 5.000$ & 1.002 & 30,89 & 855 & 23,86 & 809 & 22,13 & 737 & 20,98 \\
V & $5.000<\mathrm{P} \leq 7.500$ & 602 & 18,56 & 564 & 15,74 & 540 & 14,77 & 502 & 14,29 \\
VI & $7.500<\mathrm{P} \leq 10.000$ & 279 & 8,60 & 407 & 11,36 & 470 & 12,86 & 451 & 12,84 \\
VII & $10.000<\mathrm{P} \leq 15.000$ & 111 & 3,42 & 169 & 4,72 & 241 & 6,59 & 315 & 8,97 \\
VIII & $\mathrm{P} \geq 15.000$ & 110 & 3,39 & 162 & 4,52 & 255 & 6,97 & 308 & 8,77 \\
\hline & Jumlah & 3.244 & 100,00 & 3.583 & 100,00 & 3.656 & 100,00 & 3.513 & 100,00 \\
\hline
\end{tabular}




\section{Kebijakan pengelolaan SPP S1 reguler sesudah UKT}

Sesuai dengan Permendikbud No. 58 Tahun 2012 untuk membiayai kekurangan biaya operasional sebagai akibat tidak adanya kenaikan SPP pemerintah memberikan Bantuan Operasional Perguruan Tinggi Negeri (BOPTN) kepada PTN. Menurut Permendikbud No. 58 Tahun 2012 dana BOPTN dipergunakan untuk: 1) Pelaksanaan penelitian dan pengabdian kepada masyarakat; 2) Biaya pemeliharaan pengadaan; 3). Penambahan bahan praktikum/kuliah, 4). Bahan pustaka; 5). Penjaminan mutu; 6). Pelaksanaan kegiatan kemahasiswaan; 7). Pembiayaan langganan daya dan jasa; 8). Pelaksanaan kegiatan penunjang; 9). Pengembangan teknologi informasi dan komunikasi (TIK) dalam pembelajaran; 10). Honor dosen dan tenaga kependidikan non pegawai negeri sipil; 11). Pengadaan dosen tamu; 12). Kegiatan lain yang merupakan prioritas dalam renstra perguruan tinggi masing-masing. Namun, dana BOPTN tidak dipergunakan untuk: belanja modal dalam bentuk investasi fisik (gedung dan peralatan), tambahan insentif mengajar untuk pegawai negeri sipil, dan kebutuhan operasional untuk manajemen.

Pada tahun 2013 dan 2014 PTN Badan Hukum "XYZ" menerima danaBOPTN sebesar Rp105.176.345.000 dan Rp127.231.345.000 dan penggunaannya sudah sesuai dengan Permendikbud No. 58 Tahun 2012 yaitu untuk (a). Kegiatan penelitian dan pengabdian masyarakat, (b). Pelaksanaan kegiatan penunjang, (c). Penjaminan mutu, (d). Bahan pustaka, (e). Layanan pembelajaran, (f) Kegiatan kemahasiswaan, (g). Kegiatan prioritas Renstra. \% tase penggunaan dana BOPTN ditunjukkan pada Gambar 5 dan 6.

Tahun 2013 dana BOPTN paling besar digunakan untuk kegiatan penjaminan mutu yaitu sebesar 43\%. Selanjutnya pelaksanaan penelitian dan pengabdian kepada masyarakat 30\%, pelaksanaan kegiatan penunjang $21 \%$, dan bahan pustaka 6\%. Tahun 2014 dana BOPTN paling besar untuk kegiatan penelitian yaitu sebesar 30\%. Selanjutnya, untuk layanan pembelajaran $25 \%$, kegiatan penunjang $15 \%$, kegiatan prioritas renstra $15 \%$, kegiatan kemahasiswaan $6 \%$ dan bahan pustaka $3 \%$.

Dalam pelaksanaannya BOPTN diterima tidak diawal tahun anggaran melainkan diterima sekitar bulan Mei atau Juni, sedangkan dari bulan Januari sampai dengan April terdapat kegiatan-kegiatan yang didanai oleh BOPTN. Hal ini berpotensi dapat menghambat operasional di PTNBadan Hukum "XYZ" dan penyerapan anggaran menjadi rendah. Supaya kegiatan tersebut tetap terlaksana, maka untuk sementara waktu kegiatan tersebut didanai oleh dana prefinancing bersumber dari Dana Masyarakat (DM) yang pelunasannya menunggu dana BOPTN diterima. Permasalahannya pada tahun 2014 PTN Badan Hukum "XYZ” melakukan pinjaman sebesar 4 milyar rupiah. Pinjaman ini untuk kegiatan penelitian, karena DM (SPP UKT) yang diterima tidak cukup untuk membiayai kegiatan penelitian tersebut. Jika dilihat dari peruntukkannya, pelaksanaan penggunaan dana BOPTN di PTN Badan Hukum "XYZ" digunakan secara terikat sesuai dengan Permendikbud No. 58 Tahun 2012. Hal ini menyebabkan penggunaan dana tidak fleksibel untuk pengembangan institusi dan investasi. Selain itu BOPTN bersifat bantuan atau subsidi yang berarti bantuan ini disesuaikan dengan kondisi keuangan pemerintah. Berdasarkan kondisi tersebut, maka PTN Badan Hukum "XYZ" tetap mengutamakan penerimaan yang bersumber dari DM (SPP).

Untuk pengelolaan DM khususnya SPP dalam pelaksanaannya terdapat mismatch antara penerimaan SPPdan pengeluaranuntukbiaya operasional.Penerimaan SPP berdasarkan tahun akademik sedangkan pengeluaran untuk biaya operasional berdasarkan tahun anggaran. Dalam satu tahun akademik mahasiswa membayar SPP semester ganjil pada bulan September dan semester genap pada bulan Maret, sementara dalam satu tahun anggaran yakni dari Januari sampai Desember terjadi pengeluaran untuk membiayai kegiatan operasional. Oleh karena itu setelah penerapan kebijakan UKT sebaiknya penundaan pembayaran SPP diminimalisir agar dana SPP dapat terkumpul seutuhnya.

Sumbangan Penyelenggaraan Pendidikan (SPP) terdiri dari BPMP dan BPMK, sesuai dengan SK Rektor No. 143/I3/PP/2010 tentang Proporsi Alokasi BPMP dan BPMK Program Pendidikan Sarjana, BPMP dialokasikan untuk departemen, fakultas dan rektorat, sedangkan BPMK seluruhnya dialokasikan ke departemen/ fakultas sebagai pengampu atau penyelenggara mata kuliah. Sebelum dan sesudah UKT masih bisa tetap membiayai kegiatan operasional dan mengalokasikan SPP ke fakultas dan departemen karena masih menganut pola BPMP dan BPMK. Peraturan yang dipakai untuk menghitung pembagian BPMP masih menggunakan tarif pada SK Rektor tahun 2010 dan BPMK pada SK Rektor tahun 2008 dan 2009. SK Rektor tersebut sebaiknya diperbarui, karena untuk mencukupi kebutuhan per mata 
kuliah nilainya sudah tinggi. Sesudah UKT alokasi SPP ke fakultas/departemen berdasarkan BPMP dan BPMK dirasa sudah tidak ideal lagi, karena UKT didasarkan pada unit cost. Artinya, biaya mata kuliah didasarkan kepada kebutuhan riilnya, bukan berdasarkan tarif yang ditetapkan serta mendorong departemen agar mempunyai unit cost untuk setiap mata kuliah.

Selaras dengan pernyataan Fattah (2008) yang menyatakan terdapat beragam komponen dalam pembayaran pendidikan. Umumnya dihitung dari biaya nyata (real cost). Juanda (2012), Rosita (2014), Arfan (2015) dan Opu (2015) dalam penelitiannya menyarankan perhitungan biaya satuan (unit cost) untuk penyelenggaraan pendidikan. Menurut Juanda (2012) dan Opu (2015) bahwa untuk penyelenggaraan pendidikan memerlukan informasi biaya satuan atau unit cost.
Menurut Juanda (2012) penerapan biaya satuan atau unit cost di perguruan tinggi sangat diperlukan agar dapat memberikan gambaran bagi perguruan tinggi dalam menghitung penetapan biaya penyelenggaraan pendidikanyang sudahbarang tentuakan berbeda dengan perguruan tinggi yang lain walaupun penyelenggaraan pendidikan yang sama. Sehingga dapat dijadikan dasar bagi perguruan tinggi dalam menetapkan biaya penyelenggaraan pendidikan yang harus ditanggung oleh mahasiswa. Rosita (2014) analisis unit cost memberikan pedoman dan perencanaan pembiayaan pendidikanbagicalonmahasiswayanginginmelanjutkan pendidikan Program Pascasarjana Universitas Terbuka. Haryati (2012) dalam penelitiannya menemukan pola manajemen pembiayaan di satuan pendidikan yang berupa SOP Manajemen Pembiayaan Pendidikan dan model penghitungan unit cost per siswa per tahun per satuan pendidikan. Kedua model tersebut telah diuji coba dan terbukti efektif.

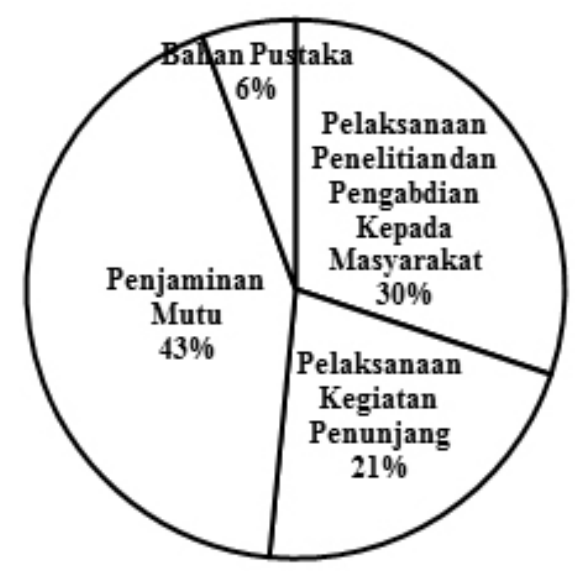

Gambar 5. Grafik \% tase penggunaan dana BOPTN tahun 2013 (Direktorat Perencanaan dan Pengembangan PTN Badan Hukum "XYZ”)

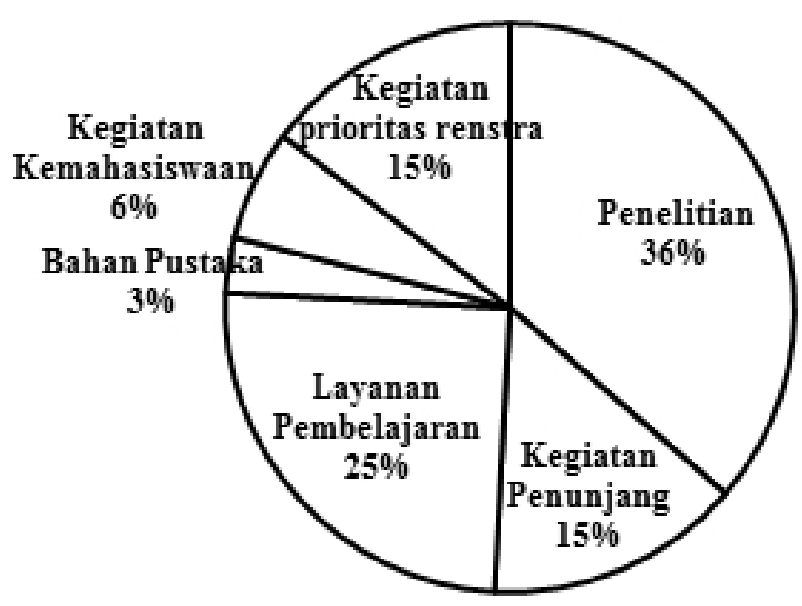

Gambar 6. Grafik \% tase penggunaan dana BOPTN tahun 2014 (Direktorat Perencanaan dan Pengembangan PTN Badan Hukum "XYZ") 
Selanjutnya Sugiyarti et al. (2013), Putra et al. (2013), Kula (2013) dalam penelitiannya dibidang kesehatan menyarankan sebaiknya pihak rumah sakit menetapkan tarif pelayanan kesehatan secara rasional untuk tiap tindakan yang dilakukan berdasarkan unit cost. Yulianisel (2015) menyatakan dengan diketahuinya biaya satuan menggambarkan besarnya biaya pelayanan yang dikeluarkan secara nyata untuk menghasilkan suatu produk pelayanan yang diberikan kepada pasien. Menurut Puspitawati dan Ratnawati (2014) Penetapan tarif layanan rawat inap non subsidi di RS Jiwa Menur selama ini karena hanya didasarkan pada perkiraan, kepantasan, dan perbandingan dengan tarif RS lain milik Provinsi Jawa Timur, karena biaya layanan belum pernah dihitung secara benar. Tarif yang tidak akurat akan memberikan informasi biaya yang terdistorsi, baik undercosting maupun over-costing yang mengakibatkan kesalahan pengambilan keputusan, penentuan biaya, pem-buatan keputusan, perencanaan dan pengendalian, serta kelangsungan RS. Tanpa memiliki angka hasil perhitungan biaya per unit (unit cost), maka proses penetapan tarif pun menjadi kurang tepat. Sugiyarti et al. (2013) menyatakan perhitungan biaya satuan (unit cost) bertujuan mendapatkan informasi mengenai perencanaan anggaran, pengendalian biaya, penetapan harga, penetapan subsidi serta membantu pengambilan keputusan. Proses perhitungan tersebut memiliki tujuan agar efisiensi dan kinerja setiap instalasi, poli maupun komponen dalam proses pelayanan di institusi penyedia pelayanan kesehatan dapat dimonitor dengan baik. Hal tersebut dilakukan agar keseimbangan antara pendapatan dengan biaya produksi rumah sakit dapat direncanakan dengan sebaik mungkin sehingga kegiatan pelayanan kesehatan kepada pasien dapat dilakukan secara optimal, tepat guna dan terjangkau bagi masyarakat.

Untuk fakultas dan departemen pelaksanaan anggarannya diturunkan kedalam SPPA (Surat Pernyataan Penggunaan Anggaran). SPPA sifatnya sebagai dasar pencairan dana. SPPA merupakan bentuk dari anggaran kas. Dengan adanya anggaran kas ini segala aktivitas dapat terkontrol. Anggaran kas juga mempunyai peranan atas operasi yang dilakukan perusahaan terutama dibidang penggunaan keuangan agar efektif dan terkontrol khususnya dalam merencanakan kas masuk dan kas keluar (Julianti et al. (2014). Selain itu dengan adanya perencanaan kas yang baik akan memastikan tersedianya dana untuk membiayai kegiatan (Seftianova dan Adam (2013).
Surat Pernyataan Penggunaan Anggaran (SPPA) fakultas berisi rincian penerimaan BPMP dan SPPA departemen berisi rincian penerimaan BPMK beserta rencana pengeluaran bulanan. Karena terdapat perbedaan waktu antara penerimaan SPP dan pengeluaran untuk biaya operasional, maka dalam SPPA baik fakultas dan departemen menggunakan periode empat belas bulan. Pada bulan Desember terdapat saldo kas surplus untuk berjaga-jaga dari Januari sampai dengan Maret, karena SPP semester genap diterima pada bulan Maret. Disburs SPPA ke masing-masing fakultas dan departemen dilakukan setiap bulan dalam satu tahun anggaran. Sementara itu, dana cadangan yang belum di disburs ke fakultas dan departemen tersimpan direkening bank mitra PTN Badan Hukum "XYZ". Menurut Junaidi (2015) dana cadangan, sebelum peruntukkannya jatuh tempo dapat digunakan untuk tujuan meningkatkan nilai dana cadangan tersebut misal dengan mendepositokan, membeli obligasi atau saham daripada menjadi uang menganggur (idle cash).

Dengan adanya SPPA dapat mengoptimalkan penerimaan sebagai sumber pembiayaan, yakni dengan cara memanfaatkan kas yang belum terpakai (idle cash). Secara lebih khusus perencanaan kas yang akurat dan tepat waktu, khususnya jangka pendek, merupakan hal yang penting dalam efektifitas pengelolaan kas (cash management). Hal ini karena perencanaan menjadi dasar bagi pengelola kas (cash manager) untuk mencari sumber-sumber pembiayaan secara lebih efisien serta melakukan optimalisasi idle cash secara lebih efektif (Muthohar, 2012).

Pemanfaatan idle cash tersebut melalui investasi jangka pendek dalam bentuk deposito/ Deposito On Call (DOC) (Datunsolong, 2010). Pemanfaatan idle cash melalui investasi jangka pendek dalam bentuk deposito/DOC sudah dilakukan dan merupakan kebijakan Kepala Biro Keuangan selaku Bendahara Institut PTN Badan Hukum" XYZ”. Namun, pelaksanaannya masih longgar. Artinya, jangka waktu yang diambil untuk investasi tersebut yaitu harian atau mingguan. Hal ini dilakukan untuk berjaga-jaga jika suatu waktu dibutuhkan dana untuk kebutuhan yang mendesak. Menurut hasil penelitian Putra dan Mashur (2014) pengelolaan anggaran kas daerah melalui pengelolaan idle cash memberikan dampak bertambahnya/meningkatnya PAD, karena ada penambahan pendapatan berupa bunga deposito. Menurut Setyowati, (2007) Idle cash dapat dicari dengan mengurangkan saldo akhir dengan saldo kas minimal sebagai cadangan. PTN Badan Hukum "XYZ" belum 
menetapkan kebijakan saldo minimal, namun ada tiga hal kebijakan yang harus diperhatikan dalam menjaga kas, yaitu menjaga cash flow sepanjang tahun akademik, harus tersedia dana cadangan, dan mempertahankan opini laporan keuangan Wajar Tanpa Pengecualian.

Selain memanfaatkan idle cash untuk mengoptimalkan penerimaan, PTN Badan Hukum "XYZ" memiliki hak otonomi dalam hal keuangan. Artinya, berhak untuk mengelola keuangannya secara mandiri yakni dengan membentuk usaha akademik, usaha penunjang, usaha komersial serta memberdayakan fasilitas-fasilitas non akademik seperti tempat parkir, sewa tempat dan lainlain sebagai penunjang pendanaan. Menurut penelitian yang dilakukan oleh Onuoha (2013), Ogbogu (2011), Apondi et al. (2014) menyatakan pentingnya peranan Internally Generated Revenue (IGR) sebagai penunjang pendanaan di universitas. Universitas federal minimum harus menghasilkan IGR 10\% dari total dana anggaran mereka setiap tahun ajaran. Selain itu dapat dilakukan dengan cara meningkatkan kegiatan Kerja sama dengan lembaga pendidikan tinggi lain, pemerintah atau swasta. Menurut Koulouris (2014) ada indikasi bahwa Kerja sama dengan lembaga-lembaga pendidikan tinggi lainnya baik di Yunani dan luar negeri dan kreativitas dianggap oleh para akademisi sebagai jawaban konsekuensi dari krisis. Untuk menunjang pendanaan sesuai dengan SK Rektor No. 09/I3/KS/2009 kegiatan Kerja sama tersebut dapat pula mencakup biaya institutional fee dengan ketentuan biaya tersebut bukan berasal dari APBN/APBD dan harus tercantum dalam Rencana Anggaran Belanja (RAB) kegiatan Kerja sama. Saat ini belum semua kegiatan Kerja sama mencantumkan biaya institutional fee dalam RAB.

\section{Implikasi Manajerial}

UKT merupakan sebagian biaya kuliah yang dibayarkan oleh mahasiswa, sehingga pemerintah memberikan dana BOPTN untuk menutupi kekurangan biaya operasional pendidikan. Namun BOPTN diterima tidak tepat waktu, penggunaannya tidak fleksible dan bersifat subsidi. Disamping itu terdapat mismatch antara jadwal penerimaan SPP dan pengeluaran untuk biaya operasional di PTN Badan Hukum "XYZ". Oleh karena itu setelah penerapan kebijakan UKT sebaiknya penundaan pembayaran SPP diminimalisir agar dana SPP dapat terkumpul seutuhnya. Selain itu untuk menunjang pendanaan, kegiatan kerjasama mencakup biaya institutional fee dengan ketentuan biaya tersebut bukan berasal dari APBN/APBD dan harus tercantum dalam Rencana Anggaran Belanja (RAB) kegiatan kerjasama. Saat ini belum semua kegiatan kerjasama mencantumkan biaya institutional fee dalam RAB.

\section{KESIMPULAN DAN SARAN}

\section{Kesimpulan}

Berdasarkan analisis rasio arus kas sebelum dan sesudah UKT, PTN Badan Hukum "XYZ" memiliki kas yang liquid artinya PTN tersebut mampu untuk mencukupi kebutuhan operasional dan program.

Uji t terhadap total penerimaan SPP TPB satu tahun pertama sebelum dan sesudah UKT berbeda nyata. Uji $t$ terhadap total penerimaan SPP mahasiswa keseluruhan mulai tahun pertama hingga tahun ke empat sebelum dan sesudah UKT tidak berbeda nyata. Artinya setelah UKT penurunan terjadi pada penerimaan SPP satu tahun pertama karena pada saat sebelum UKT pada tahun pertama terdapat komponen BPIF, sedangkan setelah UKT seluruh biaya pendidikan dibagi merata ke delapan semester. Karena penerimaan SPP tahun pertama sampai tahun keempat sebelum dan sesudah UKT tidak berbeda nyata berarti penerimaan SPP S1 Reguler tidak menurun.

Alokasi SPP ke fakultas/departemen berdasarkan BPMP dan BPMK dirasa sudah tidak ideal lagi. Hal ini dikarenakan BPMP dan BPMK didasarkan kepada sistem tarif, sehingga biaya per mata kuliah belum tentu sesuai dengan kebutuhan. Hal ini tidak sesuai dengan sistem UKT yang didasarkan pada unit cost. Artinya biaya mata kuliah didasarkan kepada kebutuhan riilnya, bukan berdasarkan tarif yang ditetapkan.

\section{Saran}

Sebaiknya memperbaiki SK Rektor tentang proporsi alokasi BPMP dan besaran biaya BPMK . Untuk BPMP masih menggunakan SK Rektor tahun 2010. BPMK bagi mahasiswa semester 3, 5 dan 7 masih menggunakan SK Rektor tahun 2008, bagi mahasiswa semester 4, 6 dan 8 menggunakan SK Rektor tahun 2009. Hal ini perlu dilakukan karena untuk mencukupi kebutuhan per mata kuliah yang nilainya sudah tinggi dan disesuaikan dengan kebutuhan riilnya. Pada penelitian selanjutnya dipertimbangkan untuk menganalisis perbedaan penerimaan SPP S1 Reguler sebelum dan sesudah UKT untuk masing-masing departemen. 


\section{DAFTAR PUSTAKA}

Apondi MU, Okelo NB, Oginda M. 2014. Role of income generating activities on performance of human resource and physical development of Maseno University - Kenya. International Journal of Marketing and Technology 4(8):5773.

Arfan T, Sari RN, Zulbahridar. 2015. Analisis biaya pada perguruan tinggi politeknik sebagai dasar penentuan biaya per mahasiswa (unit cost) : studi kasus Politeknik Caltex Riau. Jurnal Politeknik Caltex Riau 8:10-19.

Astuti VNI, Fahmi I, Hubeis M. 2015. Strategi pengembangan program penyelenggaraan khusus di pascasarjana. Jurnal Kependidikan 45(2): 184-197.

Datunsolong DC. 2010. Analisis arus kas dalam manajemen kas di Bendahara Umum Daerah (BUD) Provinsi Gorontalo [tesis]. Yogyakarta: Universitas Gadjah Mada.

Fattah N. 2008. Pembiayaan pendidikan: landasan teori dan studi empiris. Jurnal Pendidikan Dasar 9:1-4.

Haryati S. 2012. Pengembangan model manajemen pembiayaan sekolah menengah pertama (SMP) rintisan sekolah bertaraf internasional (RSBI) di Kota Magelang. Journal of Economic Education 1(1): 64-70.

Juanda A, Lestari NV. 2012. Analisis perhitungan biaya satuan (unit cost) penyelenggaraan pendidikan kedokteran(studikasus padaFakultas Kedokteran Universitas Muhammadiyah Malang). Jurnal Reviu Akuntansi dan Keuangan 2(1): 227-241.

Julianti NLE, Suwarna IK, Yulianthini NN. 2014. Penyusunan anggaran kas untuk menetapkan likuiditas dan rentabilitas pada perusahaan tahun 2013. E-Journal Bisma Universitas Pendidikan Ganesha Jurusan Manajemen 2(1).

Junaidi. 2015. Perlakuan akuntansi sektor publik desa di Indonesia. Jurnal NeO-Bis 9(1): 39-59.

Koulouris A, Moniarou-Papaconstantinou V, KyriakiManessi D. 2014. Austerity measures in greece and their impact on higher education. Procedia Social and Behavioral Sciences 147 (2014) 518526. doi : 10.1016/j.sbspro.2014.07.147.

Kula JI. 2013. Metode penetapan biaya rawat inap pada BLU RSUP Prof.Dr.R.D.Kandou Manado. Jurnal EMBA 1(3): 793-803.

Lubis MH, Sujianto. 2014. Strategi pelaksanaan surat keputusan rektor nomor 2862 tentang uang kuliah tunggal di Universitas Riau. Jurnal Online Mahasiswa (JOM) Bidang Ilmu Sosial dan Ilmu Politik 1(1): 1-10.

Muthohar A. 2012. Faktor-faktor utama yang mempengaruhi efektifitas perencanaan kas pada satuan kerja-satuan kerja kementerian negara/ lembaga dalam lingkup wilayah pembayaran KPPN Jakarta II [tesis]. Depaok: Universitas Indonesia.

Ogbogu C. 2011. Modes of funding NigerianUniversities and the implications on performance. Journal of International Education Research (JIER) 7(4): $75-82$.

Onuoha LN. 2013. Financing Higher Education in Nigeria : the role of internally generated revenues and how university managements can maximize the sources. Canadian Social Science 9(1):9-14. DOI: 10.3968/j.css. 1923669720130901.1956.

Opu NV, Suriana I, Mulyani Y. 2015. Analisis biaya satuan (unit cost) mahasiswa berdasarkan activity based costing pada politeknik " $x$ " di Balikpapan. Jurnal Sains Terapan 2(1): 78-89

Pemerintah Republik Indonesia. 2012. Undang-Undang Nomor 12 tahun 2012 tentang Pendidikan Tinggi. Jakarta: Sekretariat Negara.

Pemerintah Republik Indonesia. 2012. Peraturan Menteri Pendidikan dan Kebudayaan No. 58 Tahun 2012 tentang Bantuan Operasional Perguruan Tinggi Negeri. Jakarta: Sekretariat Negara.

Pemerintah Republik Indonesia. 2013. Peraturan Menteri Pendidikan dan Kebudayaan No. 55 tahun 2013 tentang Biaya Kuliah Tunggal dan Uang Kuliah Tunggal pada Perguruan Tinggi Negeri di lingkungan Kementerian Pendidikan dan Kebudayaan. Jakarta: Sekretariat Negara.

Putra RSP, Arifin MA, Nurhayani, Amir MY. 2013. Analisis biaya satuan (unit cost) perjenis tindakan berdasarkan relative value unit (RVU) pada bagian persalinan RSUD Ajjapange Kabupaten Soppeng tahun 2011. Jurnal AKK 2(1): 35-41.

Putra AS, Mashur D. 2014. Manajemen anggaran kas daerah. Jurnal Kebijakan Publik 4(2): 218-223.

Puspitawati DI, Ratnawati T. 2014. Analisis kinerja kemandirian keuangan dan aktivitas layanan rawat inap utama pada badan layanan umum daerah rumah sakit jiwa menur dengan metode activity based costing. DIE, Jurnal Ekonomi \& Manajemen 10(1): 16-26.

Retnani ED. 2009. Proses Penyusunan anggaran dan penilaian kinerja ditinjau dari aspek perilaku. 
Jurnal Ekuitas 13(1): 18-39.

Rosita T, Nasoha M, Isman SM. 2014. Analisis unit cost mahasiswa dalam perencanaan pembiayaan pendidikan pada program pascasarjana (pps) di Universitas Terbuka. Jurnal Pendidikan 15(1): 42-53.

Seftianova R, Adam H. 2013. pengaruh kualitas DIPA dan akurasi perencanaan kas terhadap kualitas penyerapan anggaran pada Satker Wilayah KPPN Malang. JRAK 4(1): 75-84.

Setyowati. 2007. Analisis Pengelolaan Kas Daerah Pemerintah Kabupaten Sleman untuk Peningkatan Pendapatan Asli Daerah [tesis]. Yogyakarta: Universitas Gadjah Mada.

Subani. 2015. Analisis arus kas untuk mengukur kinerja keuangan (studi pada KUD Sido Makmur
Lumajang). Jurnal WIGA 5(1): 58-67

Sugiyarti AT, Nuryadi, Sandra C. 2013. Analisis biaya satuan (unit cost) dengan metode activity based costing (abc) (studi kasus di Poli Mata RSD Balung Kabupaten Jember). Jurnal Pustaka Kesehatan 1(1): 7-14.

Wagh AD, Gadade ST. 2013. Evaluating budgeting and budgetary control process in colleges. ABINAV International Monthly Refered Journal of Research In Management \& Technology 2: 107-115.

Yulianisel. 2015. Perhitungan Unit cost tindakan bedah appendiktomi di kamar Operasi RSD Madani Provinsi Sulawesi Tengah. e-Jurnal Katalogis 3(5): 170-180. 